\title{
REWARDING SCIENTISTS WHO PURSUE AND DISCUSS PHYSICS IN THE PUBLIC INTEREST
}

\author{
David Hafemeister and Barbara Levi
}

For the most part, physics is an objective science. Physicists investigate natural phenomena and develop models that are labeled either "good" or "bad", "right" or "wrong", depending on how well they predict observed behavior. But sometimes physics is one of many factors in a complex technological problem faced by society. Then physics acquires subjective aspects. The basic physical laws may not be disputed, but the manner in which they are applied becomes controversial. For example, given all the data, physicists might agree on whether a certain space-based weapon might destroy a target under specific circumstances, but they are likely to disagree on whether it is a practical component of a particular weapons system, or on whether it can be built within a fixed time frame or budget.

The American Physical Society's Forum on Physics and Society encourages physicists to become involved in public issues, especially where physics plays a major part. Physicists can bring to these issues an understanding of the technological component, and help communicate the impact of that technology on the problem at hand. Unfortunately, there are fewer opportunities for recognition in this field than when physicists tackle more traditional problems. Some papers applying an understanding of physics to problems of society have been published in journals such as the Reviews of Modern Physics and the American Journal of Physics, especially when those papers involve equations and data. But still there are few other opportunities for peer recognition. Thus, in 1974, the Forum initiated a program of giving two awards annually for work concerning "physics in the public interest."

The past winners of the two Forum awards are listed in Table 1. They serve to illustrate the variety of topics into which physicists have channeled their interests: nuclear and chemical arms races, nuclear power, depletion of the ozone in the stratosphere, energy conservation, etc. The Szilard Award recognizes those who have constructively applied physics in the public interest. The APS Forum Award honors those who have effectively promoted public understanding of the relation of physics to society. Hopefully these awards will signify the respect accorded to physicists who have dedicated some of their professional or academic time and effort to examine some aspects of "public interest" physics.

Unfortunately, the Forum cannot afford very generous honorariums, and the cash prize sometimes appears woefully inadequate. The Forum was somewhat embarrassed in 
1985 when it had to divide the honorarium for the Szilard Award among 7 recipients who had studied nuclear winter--the two who first suggested the possibility (Crutzen and Birks) and the five who investigated it in more detail (Turco, Toon, Ackerman, Pollack and Sagan). The Forum was able to increase the total award money for that year.

\section{Past Recipients of the Szilard and APS Forum Awards}

\section{Szilard Award}

1974

1975

1976

1977

1978

1979

1980

1981

1982

1983

1984

1985

1986

1987
David R. Inglis

Bernard Feld

Richard L. Garwin

Matthew Meselson

Sherwood Rowland

Sidney Drell

Henry W. Kendall and

Hans A. Bethe

W.K.H. Panofsky

Andrei Sakharov

Kosta Tsipis

P. Crutzen and J. Birks;

R. Turco, O. Toon, T. Ackerman, J. Pollack and C. Sagan

Arthur Rosenfeld

Thomas Cockran

\section{APS Forum Award}

Ralph Lapp

Science News, a Comments Staff

Herbert F. York

Joel Primack and

Frank von Hippel

Theordore Taylor

Jeremy Stone

William Shurcliff

Philip Morrison

Bulletin of the Atomic $\underline{\text { Scientists }}$

Mike Casper

Spurgeon Kenny, Jr.

Richard Scribner

This year, the Forum supplemented financial reward with symbolic recognition by presenting each recipient with a sculpture, to keep for one year until the next year's recipient is named. The sculpture commemorating the Szilard Award is a dolphin, to symbolize Leo Szilard's novellette, The Voice of the Dolphins (1). That book tells the story of a group of smart dolphins who instruct the superpowers how to create a stable world. (An alternative interpretation is that the American and Russian scientists know that no one would listen to their own thoughts on peace so they speak their ideas through the voice of the "smart dolphins," to whom society is more willing to pay attention.) 


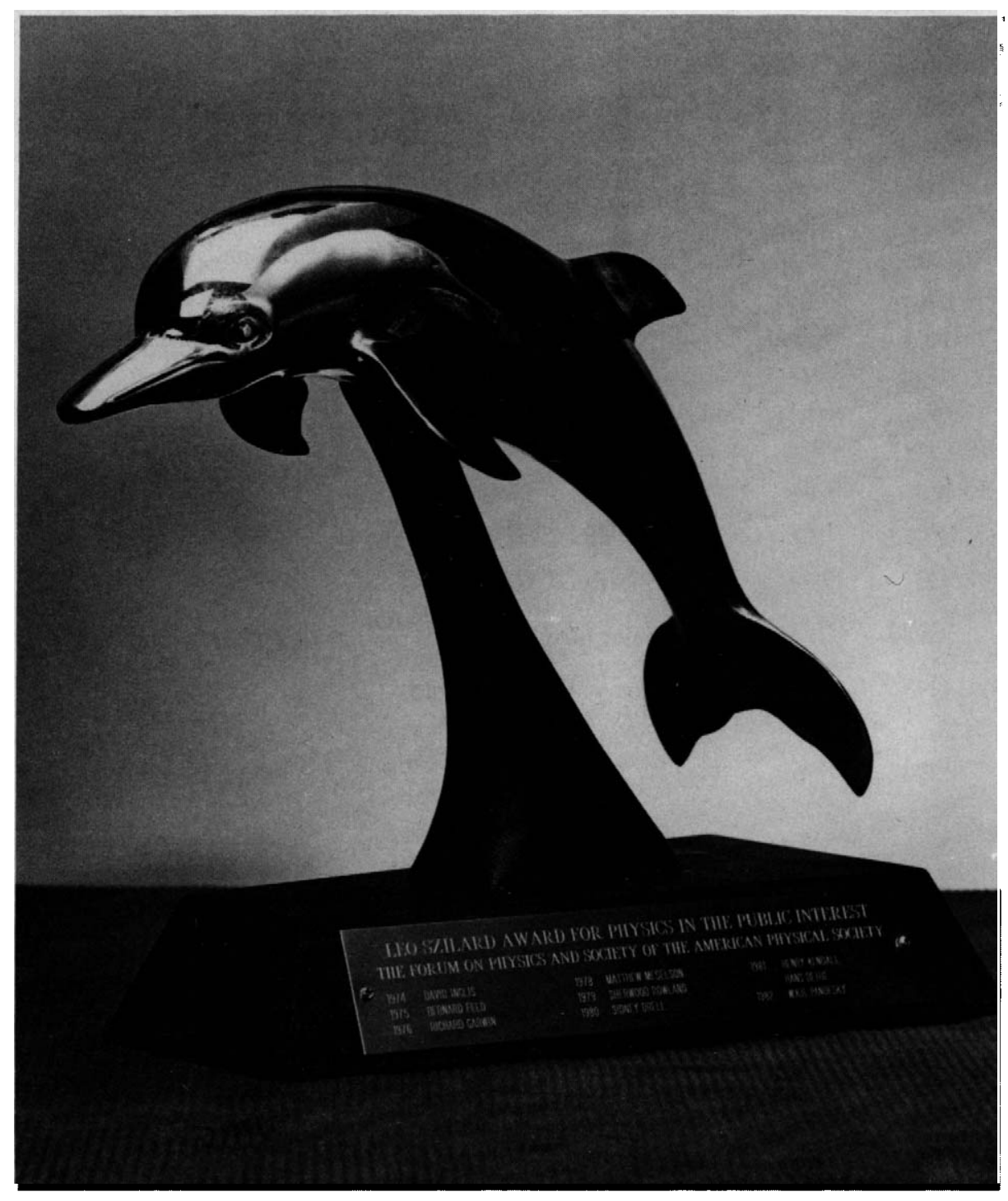

Figure 1. The Szilard Award Sculpture

The Forum is grateful to David J. Smith of the Physics Department of California Polytechnic University for generously donating the sculpture shown in Fig. 1. The sculpture commemorating the APS Forum Awrd is more abstract, as befits the more abstract task of "outreach." It is roughly spheroidal in shape and is made of hammered brass and bronze with pieces of bocote wood as shown in Fig. 2. The Forum thanks Crissa Hewitt of the Art Department at California Polytechnic University for creating the sculpture expressly for this award. 


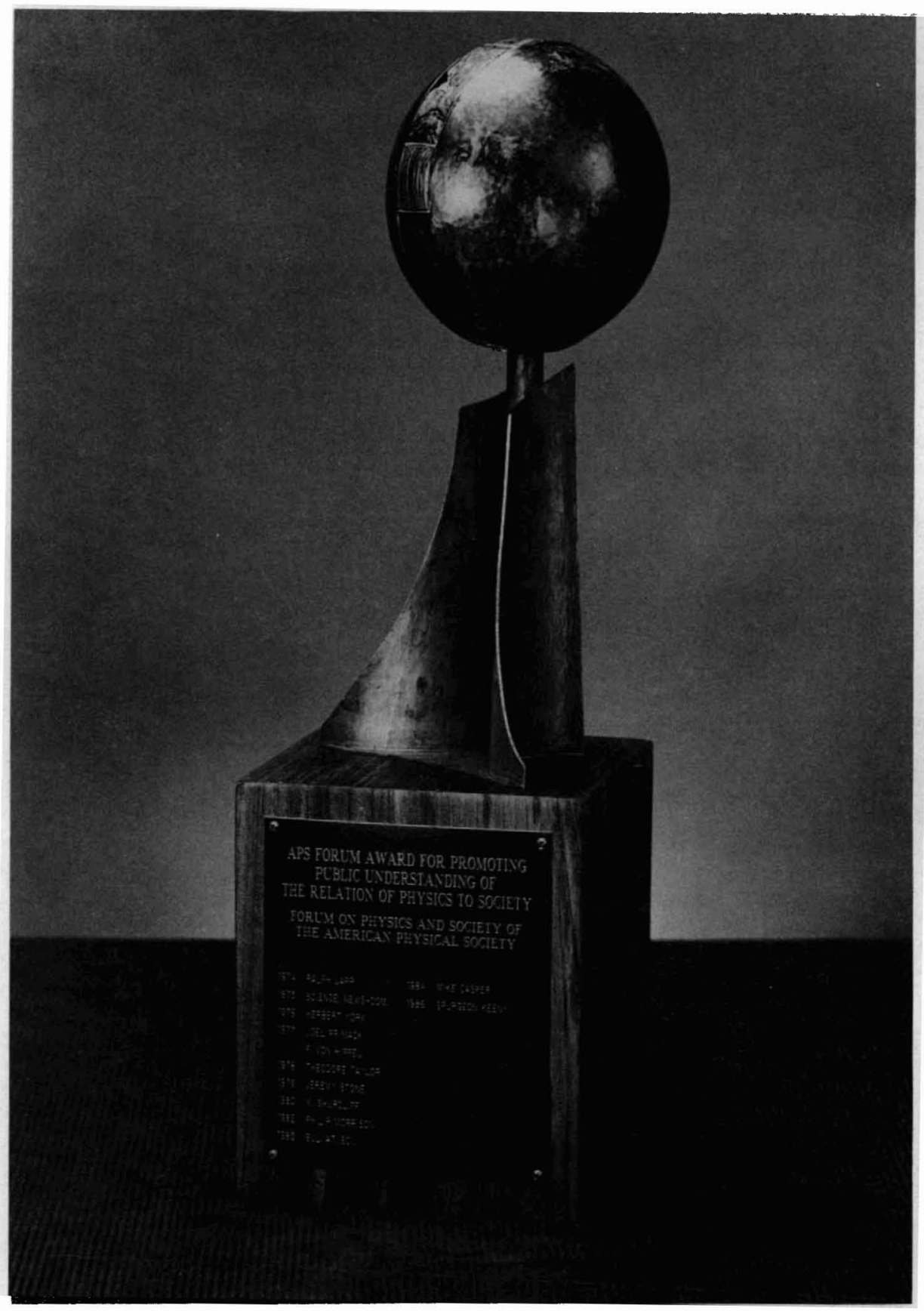

Figure 2. The American Physical Society Forum Award Sculpure 


\section{$\underline{\text { References }}$}

1. L. Szilard, The Voice of the Dolphins and Other Stories, Simon and Schuster, New York, 1961. For a recent article on the life of Szilard, see M. Bess, Bulletin, Vol. 4l, No. 12 (Dec. 1985) pp. 1l-18.

2. Aviva Brecher, 35 Madison St., Belmont, MA 02178.

3. Peter Zimmerman, Carnegie Endowment for International Peace, ll Dupont Circle, NW, Washington, DC 20036. 